\title{
Analysis of Inventory Level Optimization Using PSONN Model and Fuzzy Logic Approach
}

\author{
Yogesh \\ M. Tech. Scholar \\ Department of M.E \\ Sagar Institute of Research and Technology Excellence \\ Bhopal, India \\ yogeshyaduvanshi081@gmail.com
}

\author{
Sudhir Shrivastava \\ Assistant Professor\& Dean \\ Department of M.E \\ Sagar Institute of Research and Technology Excellence \\ Bhopal, India \\ sudhirsirte@gmail.com
}

\begin{abstract}
Raw materials, intermediate goods and finished goods are termed as inventories while considering it as portion of business's assets which can be considered as prepared or are prepared for sale. One of the suitable solutions is to design optimal inventory model. Major concern of industry is to design suitable inventory model. Some of the existing inventory management research work are discussed in literature. But this field is still a big area of interest. Many research works used artificial intelligence models for inventory management. One amongst the area for inventory management is worker behavior in a company. So, employees are taken into account to be as an inventory that contributes in growth of an organization. Employee attrition may be a big issue for the organizations specially once trained, technical and key staff leave for a far better chance from the organization. This results in financial loss to replace a trained employee. Therefore, this paper uses the current and past employees' data to analyze attrition behavior of employees and to provide bonus/promotion to employees having non attrition behavior by using PSONN and fuzzy rules. The result shows that the efficiency of model is improved with respect to existing methods by approximately $2 \%$.
\end{abstract}

Keywords - Raw materials, Inventories, Inventory Management, Artificial Intelligence, Fuzzy rules.

\section{I.INTRODUCTION}

Inventory is an accounting term that refers to goods that are in various stages of being made ready for sale, including: Finished goods (that are available to be sold) Work-in-progress (meaning in the process of being made) Raw materials (to be used to produce more finished goods). All the materials, parts, suppliers, expenses and in process or finished products recorded on the books by an organization and kept in its stocks, warehouses or plant for some period of time. One amongst the area for inventory management is worker behavior in a company. So, employees are taken into account to be as an inventory that contributes in growth of an organization. Whenever an employee leaves an organization, there is a source of advantage for the business competitor because of the invaluable tacit knowledge that the employee carries with them. Therefore, to be continuously competitive in the business, the organization should minimize the employees' attrition.

"Predicting the employee attrition and the reason for an employee leaving an organization" was performed to perceive the reasons, why the best and most experienced employees quit the company prematurely and try to predict which valuable employees are probable to leave the organization subsequently so as to find the areas where the organization is lagging behind. This model can be used by the Human Resource departments of the organizations to form efficient strategies to retain the valuable employees before they start looking for new jobs like by providing a hike in their salary, offering promotions if necessary, travel and stay abroad or start the hiring process.

As in [1], attrition is defined as the normal and uncontrollable reduction of a work force because of retirement, death, sickness, and relocation. There are two types of employee turnover which are voluntary (turnover initiated by the employee) and involuntary (turnover initiated by the organization). This paper only focuses on the voluntary turnover. Involuntary turnover is not being concerned much because the decision is indeed made by the organization due to reasons like recession, retirement, death or in rare cases can be misconduct of the employee.

Most companies face a formidable challenge of recruiting and retaining talents while at the same time having to manage talent loss through voluntary 
employee attrition. Attrition becomes a problem to the company, considerably when an IT professional leaves an organization as this reduces the number of employees working for assignment. The professionals also take with themselves the tacit knowledge and the understanding of the specific business operations. Losing talented employees result in performance losses if the departing talent leaves gaps in its execution capability and human resource functioning which not only includes lost productivity but also possibly loss of work, team harmony and social goodwill. Nowadays the Human Resource department is greatly interested in reducing Attrition in the organization.

\section{II.RELATED WORK}

Alduayj et al. [2] studies employees' attrition using machine learning models. Using a synthetic data created by IBM Watson, three main experiments were conducted to predict employee attrition. The first experiment involved training the original classimbalanced dataset with the following machine learning models are: support vector machine (SVM) with several kernel functions, random forest (RF) and $\mathrm{K}$-nearest neighbor (K-NN) above mentioned machine learning models.

Ford W. Harris [3] developed the first mathematical model for inventory management, the Economic Order Quantity Model (EOQ), introduced in 1913. It was designed for production planning purposes. EOQ is a dynamic and deterministic mono-product model, essentially very simple. The model indicates the optimal solution for knowing the behavior of the inventory system. The closed solution is also easy to calculate.

Pikulkaew Tangtisanon [4] focused on an inventory management and a stock forecasting system. Web service was implemented as a new approach for an inventory management system that helps to manage and to find the food additives that exist in the international food additive database authorized by Codex Alimentarius Commission. The stock forecasting was done with four machine learning models which are Naive Bayes, Decision Tree, Linear Regression and Support Vector Regression to predict stock of food additive.

Hsiao Ching Chen [5] developed a system of intelligent agents to simulate the supply chain system. The artificial neural network (ANN) is used to derive optimal inventory policies. The proposed inventory decision, which uses an intelligent agent and an artificial neural network, provides management information on the impact of decision making on the factory, wholesale, distribution and distribution markets.

Hachicha [6] utilized an AI and worked with the lotsizing problem in supply chains by applying a meta modelling simulation. The supply chain is handled in a make-to-order environment (no possibility of keeping stock and limited production capacity). The model is designed for multi-product, multi-stage and multi-location production planning with capacity constraints and stochastic parameters such as lot arrival orders, transit time, set-up time, processing time and so on.

Paul and Azaeem [7] have developed another model based on artificial intelligence that determines the optimal state of the finished product. The inputs for this model include product demand, equipment, storage and material costs from which the data comes from a manufacturing sector. The results showed that the model can be used to predict the stock of finished products in response to the input parameters of the model. In general, the constructed model can be applied to the optimization of the stock of finished products in each manufacturing company.

The inventories mentioned by Shrivastava [8] are raw materials, products in progress and completely finished products, which are considered part of the assets of the company ready for sale. Developing an appropriate inventory model is a major concern in any industry. The first scientific studies on inventory management date back to the second decade of the last century, but interest in this scientific area remains high. Once again, the reliability of a process is an important feature of research activities. The values of some factors are very difficult to define or almost unreal. In these cases, AI inventory models are important.

This research work is focused on finding a well trained and experienced employees, in any organization, for giving bonus or for replacement. Hiring new employees always costs organization some huge costs. Human Resource departments generate an enormous amount of data on a daily basis: leaves, social conflicts, annual evaluations, wages and benefits, recruitments, departures, career evaluations, etc. But the big dilemma is to find out the correct and accurate replacement of the employees who will left.

Here are some of the challenges faced by the hiring managers: 
1. Eligible Candidates Finding and sorting the best candidates.

2. Another area of research is to find out the candidates that would prove to be an asset to the firm if hired.

3. If a selected candidate drops off, then firm have to repeat the cycle of complete processes and find a replacement again.

\section{III.METHODOLOGY}

\section{Methodology Consists of Following Phases:}

1. The dataset is taken.

2. The Useful information are selected for deciding Attrition of Employees using Co-relation Analysis (Spearman, Kendall and Pearson).

3. Classifying new employees for their attrition behaviour using PSONN.

4. Non-attrition employees and not decidable employees are further considered for bonus for which fuzzy rules are designed.

Finding Spearman, Kendall and Pearson Corelation:

Spearman Co-relation: coefficient $\sigma$ is calculated by the formula mentioned below:

$$
\sigma=1-\left(6 \Sigma \mathrm{d}_{\mathrm{i}}^{2}\right) / \mathrm{n}\left(\mathrm{n}^{2}-1\right)
$$

Where,

$\mathrm{d}_{\mathrm{i}}=$ difference between variables $\mathrm{P}$ and $\mathrm{Q}$

$\mathrm{n}=$ sample size

Kendall Co-relation: coefficient $\tau$ is calculated by the formula as given below:

$$
\tau=\left(\mathrm{n}_{\mathrm{c}}-\mathrm{n}_{\mathrm{d}}\right) /(1 / 2 \mathrm{n}(\mathrm{n}-1))
$$

Where,

$\mathrm{n}_{\mathrm{c}}=$ number of concordant values (if $\mathrm{x}_{\mathrm{i}}<\mathrm{x}_{\mathrm{j}}$ )

$\mathrm{n}_{\mathrm{d}}=$ number of discordant values (if $\mathrm{x}_{\mathrm{i}}>\mathrm{x}_{\mathrm{j}}$ )

$\mathrm{n}=$ sample size

Pearson Co-relation: coefficient $\rho$ is calculated by the formula as given below:

$$
\rho=\frac{E[A D]-E[A] E[D]}{\sqrt{E\left[A^{2}\right]-(E[A])^{2}} \sqrt{E\left[D^{2}\right]-(E[D])^{2}}}
$$

Where,

A = first element (attribute)

$\mathrm{D}=$ second element (attribute)

$\mathrm{E}=$ sum of the elements

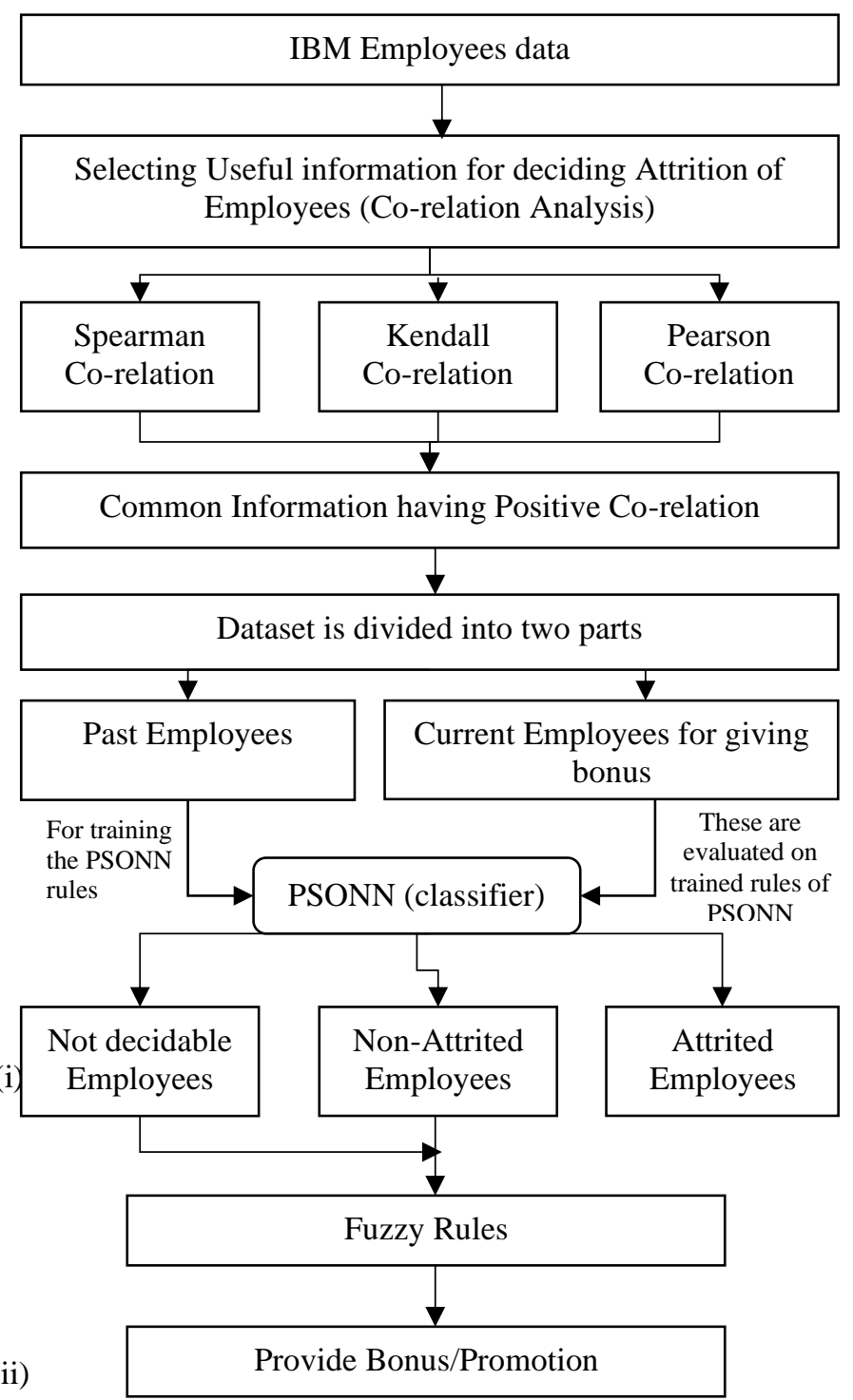

Figure 1: Methodology for Employees Attrition

Detection

Particle Swarm Optimized Neural Network (PSONN):

It presents an intelligent and an optimal model using hybridization of Artificial Neural Network (ANN) and Particle Swarm Optimization (PSO). Artificial network (iii) simple three-layer neural network having one input, hidden layers and output layer. The number of input layer neurons are equals the number of inputs as shown below in figure 2 .

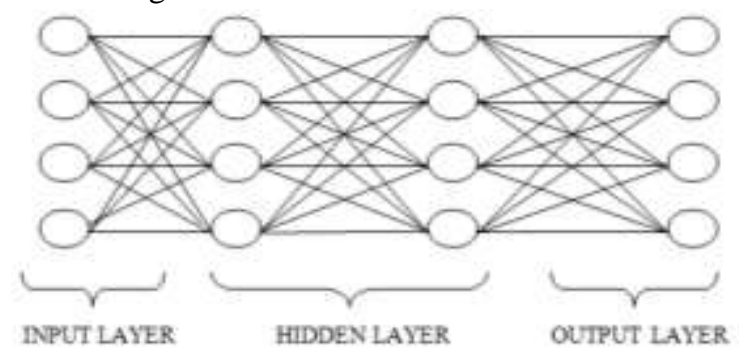

Figure 2: ANN Architecture Example 
ANN example is explained in below figure 3. In artificial neural network currently predicts weights and biases. To predict weight and bias, data are inserted and forwarded though the entire network.

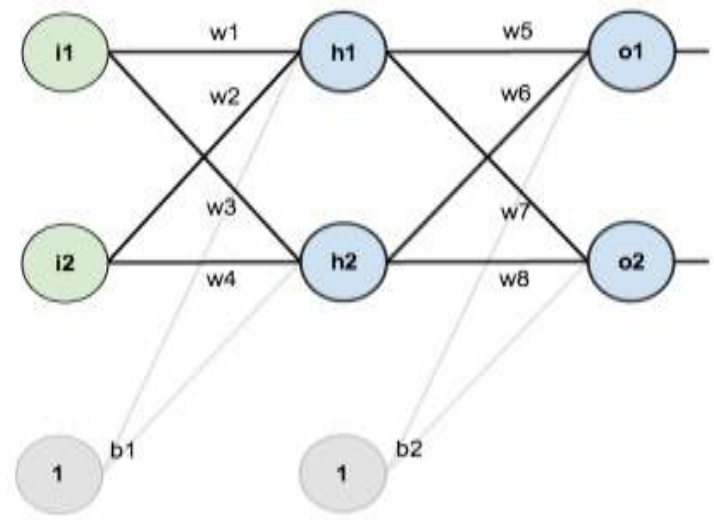

Figure 3: Neural Network

The total net input to each hidden layer neuron is the total net input using an activation function, then repeat the process with the output layer neurons. So, the total net input for $\mathrm{h}_{1}$ as in equation (iv) and equation (v).

$$
\text { net }_{h_{1}}=w_{1} * i_{1}+w_{2} * i_{2}+b_{1} * 1
$$

Then sum of layer to get the output of $h_{1}$

$$
\text { out }_{h_{1}}=\frac{1}{1+e^{- \text {neth }_{1}}}
$$

Further carrying out the same process for $h_{2}$ in above figure 3. Then process is repeated for the output layer neurons, using the output from the hidden layer neurons as inputs. Here's the output for $\mathrm{o}_{1}$ as in equation (vi).

$$
\text { net }_{o_{1}}=w_{5} * \text { out }_{h_{1}}+w_{6} * \text { out }_{h_{2}}+b_{2} * 1
$$

And carrying out the same process for $\mathrm{O}_{2}$. Then error is calculated for each output neuron using the squared error function and sum them to get the total error as in equation (vii).

$$
E_{\text {total }}=\sum \frac{1}{2}(\text { target }- \text { output })^{2}
$$

The working of the neural network is focused towards adjusting the weights associated with entire network in order to reach the target data values, for minimizing the error between output and target values.

These obtained links in entire network are further optimized (reduced), only best links are selected with minimum error rate, using PSO algorithm.

\section{PSO Algorithm works as:}

1. (Initialization) Randomly generate initial particles (links) in groups.

2. (Fitness) Measure the fitness of each particle in the population.

www.ijoscience.com
3. Find best fitness value link termed as Pbest.

4. Among all Pbest find the best value called Gbest.

5. (Termination) Stop the algorithm if the termination criterion is satisfied; return to Step 2 otherwise.

\section{Fuzzy Rules Designed for Employees Promotion Prediction:}

After selecting Non-attrition employees and not decidable employees, bonus/promotion prediction is performed by designing fuzzy rules as shown in below figure 4.

Four most important features (out of 23 features) are selected for designing fuzzy rules which are:

1. JobSatisfaction (1-5 rating)

2. NumCompaniesWorked (0-9 years)

3. PerformanceRating ( 1-5 rating)

4. TotalWorking Years ( $0-40$ years)

On these four features total 495 rules are designed (i.e. ${ }^{12} \mathrm{C}_{4}$ ) which select best employees for bonus (iv) distribution or promotion application.
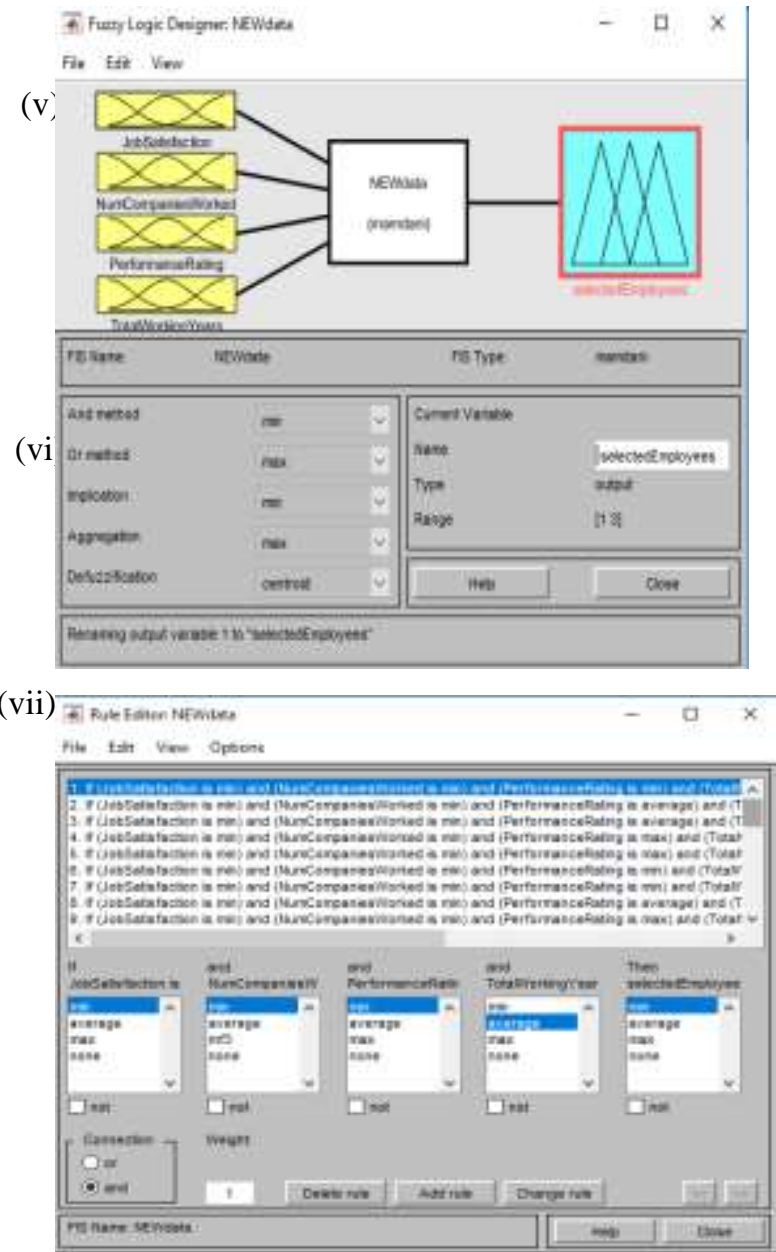

Figure 4: Fuzzy Rules Designed for Employees Promotion Prediction 


\section{IV.RESULTS AND DISCUSSIONS}

In order to evaluate the performance of methodology, the proposed algorithm is simulated in following configuration:

\section{Pentium Core I5-2430M CPU @ $2.40 \mathrm{GHz}$ \\ 2. 4GB RAM \\ 3. 64-bit Operating System \\ 4. MATLAB Platform}

For simulation result, the research is focused towards co-relation feature extraction for attrition analysis from employees. For executing this simulation, IBM employee's dataset is prepared with 1470 employees. The result analysis is performed to find accuracy of the proposed methodology and to decide the behaviour of the employees either it is of attrition or not.

\section{Accuracy $=(\mathbf{T P}+\mathbf{T N}) /(\mathbf{T P}+\mathbf{T N}+\mathbf{F P}+\mathbf{F N})$}

Where,

$\mathrm{TP}=$ True Positive, that means if employee is of attrition behavior and the predicted label also stands for attrition behavior.

$\mathrm{TN}=$ True Negative, that means if employee is of nonattrition behavior and the predicted label also stands for non-attrition behavior.

FP = False Positive, that means if employee is of nonattrition behavior and the predicted label stands for attrition behavior.

$\mathrm{FN}=$ False Negative, that means if employee is of attrition behavior and the predicted label stands for non-attrition behavior.

Table I: Performance Evaluation for PSONN Algorithm

\begin{tabular}{|c|c|c|c|c|}
\hline $\begin{array}{c}\text { No. of } \\
\text { Employees } \\
\text { (out of } \\
\text { 1470) }\end{array}$ & $\begin{array}{c}\text { Accuracy } \\
\text { (in \%) }\end{array}$ & Attrition & $\begin{array}{c}\text { Non- } \\
\text { Attrition }\end{array}$ & $\begin{array}{c}\text { Not- } \\
\text { Decided }\end{array}$ \\
\hline 220 & 94.09 & 19 & 188 & 13 \\
\hline 294 & 93.19 & 23 & 251 & 20 \\
\hline 441 & 92.97 & 34 & 376 & 31 \\
\hline 588 & 92.51 & 44 & 500 & 44 \\
\hline 735 & 92.51 & 63 & 617 & 55 \\
\hline
\end{tabular}

www.ijoscience.com
For this the research methodology is designed using PSONN for predicting either attrition or non-attrition behavior of the employees. These evaluations are performed on testing dataset. The training testing dataset is divided into $85: 15$ ratio, 80:20 ratio, 70:30 ratio, 60:40 ratio and 50:50 ratio. The table I gives the performance of PSONN algorithm for employees' attrition prediction in terms of accuracy.

Table II: Selected Employees for Bonus/Promotion

\begin{tabular}{|c|c|}
\hline $\begin{array}{c}\text { No. of } \\
\text { Employees }\end{array}$ & Selected Employees Id for bonus \\
\hline 10 & $\begin{array}{l}1034,1036,1040,1043,1049,1050 \\
1057,1062,1070,1072\end{array}$ \\
\hline 20 & $\begin{array}{l}1034,1036,1040,1043,1049,1050 \\
1057,1062,1070,1072,1073,1079 \\
1080,1085,1092,1096,1099,1107 \\
1108,1110\end{array}$ \\
\hline 30 & $\begin{array}{l}1034,1036,1040,1043,1049,1050 \\
1057,1062,1070,1072,1073,1079 \\
1080,1085,1092,1096,1099,1107, \\
1108,1110,1112,1115,1116,1124, \\
1130,1134,1137,1144,1145,1146\end{array}$ \\
\hline 40 & $\begin{array}{l}1034,1036,1040,1043,1049,1050, \\
1057,1062,1070,1072,1073,1079, \\
1080,1085,1092,1096,1099,1107, \\
1108,1110,1112,1115,1116,1124, \\
1130,1134,1137,1144,1145,1146, \\
1149,1150,1151,1152,1153,1164, \\
1173,1175,1179,1185\end{array}$ \\
\hline 50 & $\begin{array}{l}1034,1036,1040,1043,1049,1050 \\
1057,1062,1070,1072,1073,1079 \\
1080,1085,1092,1096,1099,1107, \\
1108,1110,1112,1115,1116,1124, \\
1130,1134,1137,1144,1145,1146, \\
1149,1150,1151,1152,1153,1164, \\
1173,1175,1179,1185,1194,1199 \\
1231,1232,1238,1246,1253,1257 \\
1260,1266\end{array}$ \\
\hline
\end{tabular}

The table II gives a sample of selected employees out of 441 employees testing sample of employees for providing bonus/ Promotion. The sorted list of selected employees ID of IBM employees are given in the table.

Table III: Comparative Performance Evaluation

\begin{tabular}{|l|c|}
\hline Methodology & Accuracy (in \\
\hline Proposed PSONN & 93.05 \\
\hline Random Forest [2] & 91.4 \\
\hline
\end{tabular}




\begin{tabular}{|c|c|}
\hline SVM [2] & 85.1 \\
\hline K-NN [2] & 86.9 \\
\hline
\end{tabular}

The table III and figure 5 gives a comparative result analysis of proposed work with existing work that was performed on three different classifiers such as Random Forest (RF), Support Vector Machine (SVM) and K-Nearest Neighbor (K-NN). The result shows the enhancement of proposed work with approx. $2 \%$ and the work is also extended towards the finding employees which can be selected for providing bonus or promotion which was not discussed in existing work.

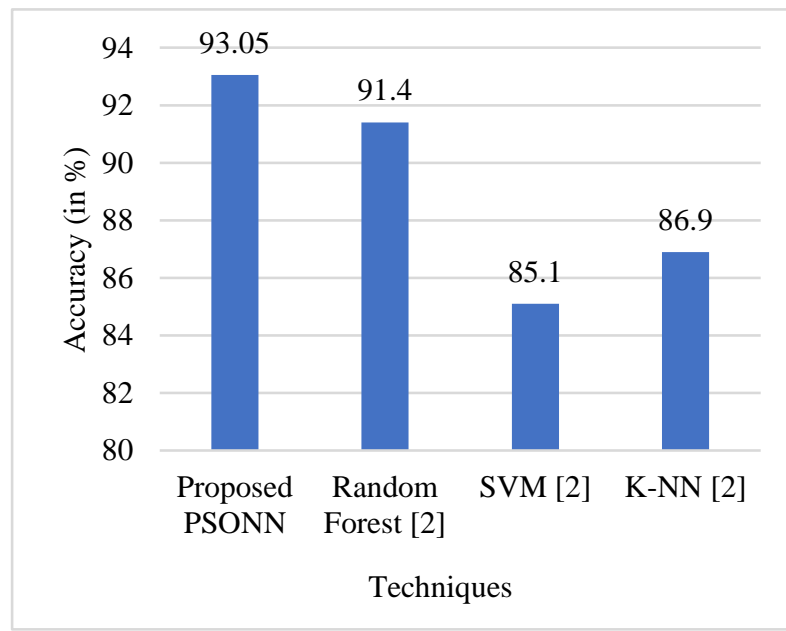

Figure 5: Comparative Accuracy Evaluation

\section{V.CONCLUSION}

Employee attrition is a trivial issue for organization's loss such as financial loss, cost and time to get the replacement and hiring, retraining of new employees and also customer dissatisfaction. Somehow organization can bear the loss of attrition of employees that are not as much experienced as those who has spent a significant amount of time that their attrition always results in some serious losses. Employee attrition can have a negative impression on existing employees. HR department may do partiality in manual evaluation of employees for bonus. Employee attrition can affect an organization in many ways like goodwill, revenues and cost in terms of both time and money. The predictive attrition model helps in not only taking preventive measure, but also making better hiring decisions as well as providing appreciations to best employees that contributes to the benefit of the organization. In this research work, PSONN is designed to predict attrition behavior of the employees. Some of the important facts analyzed and concluded in this work are stated as below:
1. In this research work, PSONN is designed to predict attrition behavior of the employees. The result shows that the efficiency of model is approx. 94\% and shows improved performance with existing methods by approx. $2 \%$.

2. This model is quite efficient for finding eligible candidates for finding and sorting the best and deserving candidates.

3. This model also gives motivational message to existing employees to do their work with dedication and deserving candidates will definitely get promotion/bonus without any partiality.

4. This model also helps in finding such candidates that are proved to be an asset to the firm if hired.

5. This decision support system also efficient with respect to time.

6. This model gives decision for bonus and promotion without any partiality and indirectly helps in development of the organization.

\section{REFERENCES}

[1] Alao D. \& Adeyemo A. B, Analyzing Employee Attrition Using Decision Tree Algorithm, Computing, Information Systems \& Development Informatics, 4(1), 2013, 17-28.

[2] Alduayj, Rajpoot, "Predicting Employee Attrition using Machine Learning", International Conference on Innovations in Information Technology, IEEE, 2018.

[3] Ford Whitman Harris, "Economic Order Quantity Model", Institute for Operations Research and the Management Sciences (INFORMS), 24 December 2018.

[4] Pikulkaew Tangtisanon, "Web Service Based Food Additive Inventory Management with Forecasting System", International Conference on Computer and Communication Systems (ICCCS), 2018.

[5] Hsiao Ching Chen ; Hui Ming Wee ; Yao-Hung Hsieh, "Optimal Supply Chain Inventory Decision Using Artificial Neural Network", WRI Global Congress on Intelligent Systems, 2009.

[6] Hachicha, W. A simulation meta modelling based neural networks for lot- sizing problem in MTO sector. Journal of Simulation Modelling. 2011;10(4): 191-203. DOI: 10.2507/IJSIMM10(4)3.188

[7] Paul, S. K., Azaeem, A. An artificial neural network model for optimization of finished goods inventory. International Journal of Industrial Engineering Computations. 2011;2(2):431-438. DOI: $10.5267 /$ j.ijiec.2011.01.005.

[8] Y., \& Shrivastava, S., "Analysis of Inventory Level Optimization Using Artificial Intelligence Approach.” IJOSTHE, 7(2), 8, 2019. Retrieved from https://ijosthe.com/index.php/ojssports/article/view/90 